\title{
Health-related quality of life in long-term survivors of childhood brain tumors: a population-based cohort study
}

\author{
Lisa Ljungman ${ }^{1}(1) \cdot$ Tiina Remes $^{2,3}$ - Elisabeth Westin ${ }^{1} \cdot$ Alina Huittinen $^{1} \cdot$ Tuula Lönnqvist $^{3} \cdot$ Kirsti Sirkiä $^{4}$. \\ Heikki Rantala $^{2} \cdot$ Marja Ojaniemi $^{2} \cdot$ Marika Harila $^{5} \cdot$ Päivi Lähteenmäki $^{6} \cdot$ Pekka Arikoski $^{7} \cdot$ Anna Wikman $^{1}$. \\ Arja Harila-Saari ${ }^{1}$
}

Received: 4 October 2021 / Accepted: 9 February 2022 / Published online: 3 March 2022

(c) The Author(s) 2022

\begin{abstract}
Purpose Survivors of childhood brain tumors (BT) are at high risk for long-term physical and psychological sequelae. Still, knowledge about health-related quality of life (HRQL) and associated factors in this population is sparse. This study investigated HRQL and its predictors in long-term survivors of childhood BT.

Methods Survivors of childhood BT (mean age $=28.1$ years, $\mathrm{SD}=6.8, n=60$ ) underwent clinical examination and neurocognitive examination, and completed self-rating questionnaires assessing HRQL (RAND-36) and depressive symptoms (Beck Depression Inventory-II). Socio-demographic information was gathered via a questionnaire. Tumor- and treatment-related information was collected from medical records. Control group data were collected from age-matched controls $(n=146)$ without a history of cancer, randomly selected from the local population registry. Multiple linear regression models were used to investigate predictors of HRQL; separate models were fitted for each domain of the RAND-36.

Results Male survivors (mean age $=27.0, \mathrm{SD}=6.0, n=39$ ) reported significantly lower HRQL than male controls in the domains of physical functioning, general health, vitality, social functioning, and role limitations-emotional. Female survivors (mean age $=30.2$ years, $\mathrm{SD}=7.6, n=21$ ) reported comparable levels as female controls in all domains except physical functioning. A higher burden of late effects, not working/studying, being diagnosed with BT during adolescence, and reporting current depressive symptoms were significant predictors of lower HRQL.

Conclusion Our results highlight that male survivors of childhood BT are at particular risk of impaired HRQL. Also, results point to the close relation between symptoms of depression and impaired HRQL in survivors of childhood BT which should be acknowledged by long-term follow-up care.
\end{abstract}

Keywords Brain tumor $\cdot$ Childhood cancer $\cdot$ CNS tumor $\cdot$ Depression $\cdot$ Health-related quality of life $\cdot$ Radiation therapy . Survivors

Lisa Ljungman and Tiina Remes share joint first authorship.

Lisa Ljungman

lisa.ljungman@kbh.uu.se

1 Department of Women's and Children's Health, Uppsala University, Uppsala, Sweden

2 Department of Pediatrics and Adolescence, PEDEGO Research Unit and Medical Research Center, Oulu University Hospital, University of Oulu, Oulu, Finland

3 Department of Child Neurology, Children's Hospital, Helsinki University Hospital, University of Helsinki, Helsinki, Finland
4 Department of Pediatrics and Adolescence, Helsinki University Hospital, Helsinki University, Helsinki, Finland

5 Department of Neurology, Oulu University Hospital, Oulu, Finland

6 Department of Pediatrics and Adolescent Medicine, Turku University Hospital, Turku University, Turku, Finland

7 Pediatric Research Unit, Kuopio University Hospital, University of Eastern Finland, Kuopio, Finland 


\section{Introduction}

The survival rate for childhood brain tumors (BT) in the Nordic countries is approaching $80 \%$ [1]. With an increased number of long-term survivors, the focus on late effects and quality of survival has increased accordingly [2]. Compared to survivors of other childhood malignancies, childhood BT survivors are well-known to be at higher risk of serious medical illnesses, functional impairment, and late mortality [3-5]. Medical conditions commonly reported in this population include endocrinological, cardiovascular, and cerebrovascular late effects, as well as cognitive impairment and sensory health conditions $[4,6]$. Additionally, BT survivors may suffer from fatigue, pain, emotional disorders, and changes to physical appearance and body image [3, 7]. Compared with healthy controls, BT survivors also report higher rates of attention deficits, peer conflict, social withdrawal, and antisocial behavior [8]. Despite all these well-documented common impairments in physical, neurocognitive, and psychosocial function, firm knowledge about health-related quality of life (HRQL) in long-term survivors of childhood BT is lacking.

HRQL is a multidimensional construct reflecting the impact that health and illnesses may have on well-being with respect to physical as well as emotional, social, and cognitive functioning $[9,10]$. The previous literature on the level of HRQL in survivors of childhood BT has been inconclusive, with some studies reporting HRQL in this population to be comparable to healthy controls [11, 12], while others report HRQL to be impaired compared to survivors of other childhood malignancies [13, 14]. It has also been reported that over the course of time, HRQL seems to progressively decline in survivors of childhood BT [15]. Furthermore, previous research has suggested that the domains of social function, physical function, role limitations due to physical problems, general health, and bodily pain seem to be most affected in survivors of childhood BT [16-18].

Regarding predictors of HRQL in long-term survivors of childhood BT, a previous systematic review reported that hypothalamic tumor involvement, osteopenia, need for special education, older age at diagnosis, and radiotherapy (RT) are associated with lower levels of HRQL [19]. Also, children diagnosed and treated during adolescence have been reported to experience a lower HRQL than children diagnosed at an earlier age [20]. Research has shown that having been treated with a ventriculoperitoneal shunt, on the other hand, has been associated with better long-term HRQL [21]. Overall, the effect of treatment variables on HRQL in survivors of BT has, however, been reported to be minor, whereas current health problems have been more strongly associated with decreased HRQL [8]. In particular, current psychosocial, cognitive, and neurological problems have been shown to be related to levels of HRQL [16]. The few previous studies that have investigated HRQL in relation to gender in this population have been contradictive, with some reporting no effect of gender $[21,22]$ while others have reported that female gender is a predictor of lower HRQL [23]. Since females in general report lower HRQL than males, it is important to use gender-specific control groups and gender-specific norms to interpret the level of HRQL among survivors of BT. Still, in the previous literature in this field, this has not been done, thus hampering conclusions regarding effects on HRQL in this population [24, 25].

Taken together, previous reports on HRQL in long-term survivors of childhood BT have been inconclusive. Inconsistencies in methodology such as the use of non-validated measurements of HRQL and mixed samples with regard to treatment, time of follow-up, gender, and the burden of late effects have been brought up as reasons for these mixed results. The aim of this study was therefore to determine HRQL in male and female long-term childhood BT survivors ( $>16$ years of age), respectively, by using a well-validated measurement and age- and gender-matched control groups. A further aim was to study the medical, physical, neurocognitive, psychological, and socio-demographic factors associated with HRQL in long-term survivors of childhood BT. By establishing this knowledge, long-term followup care can be better adapted to the needs of this population, and individuals at particular risk of low HRQL can be identified and provided with adequate care and support.

\section{Methods}

\section{Design}

The study used a population-based cohort design.

\section{Participants and procedure}

A national cohort of childhood BT survivors who were diagnosed between 1970 and 2008 with BT up to the age of 16 and treated with RT was identified from the registers at Oulu, Kuopio, Turku, Tampere, and Helsinki university hospitals. Additional inclusion criteria for the study were as follows: being at least 16 years of age at the time of the study, having a follow-up time since cessation of all tumor therapies of at least 5 years, and having no other progressive BT known at the time of the study. Eligible participants $(n=127)$ were contacted by letter, including information about the study and its procedure. Potential participants who did not respond were thereafter contacted by phone. The 
current study is part of a larger study of childhood BT survivors conducted in 2010-2015 (for a more thorough description of the study procedure, please see Remes et al. [26]). Written informed consent was obtained from all participants or their legal guardians.

For the data collection, participants underwent a 2-day clinical examination, including blood samples, craniospinal magnetic resonance imaging (MRI), and neuropsychological examination. Participants also answered survey questions about socio-demographic information and completed self-assessment scales of HRQL, function in daily life, and depression and anxiety. The survey questions and the selfassessment scales were either filled in solely by the participant or, if needed, with some assistance from a caregiver, parent, or a researcher. Medical records were examined to study the treatment of the brain tumor and the possible presence of late effects. Information from medical records was used for classification of potential late effects. For the present study, cross-sectional data from the follow-up assessment were used.

The institutional review boards of the Oulu, Kuopio, Turku, Tampere, and Helsinki university hospitals, Finland, approved the study. The research was conducted according to the principles of the Declaration of Helsinki.

\section{Controls}

A random sample of age-matched controls was collected from the local population registry. A total of 370 healthy young adults were contacted by letter including information about the study and its procedures. Of these, 146 individuals participated, representing a response rate of 39\%. Data from the controls has also been used in a previous study, where they were matched regarding age, gender, and living area to patients included in a previous leukemia study; see Harila et al. [27] for a more thorough description of the procedure for collecting data from the controls. The participants completed the same survey as the survivors including questions about socio-demographic information and self-assessment scales of HRQL, function in daily life, and depression and anxiety.

\section{Measurements}

\section{Health-related quality of life}

HRQL was assessed using the RAND-36 [24]. RAND-36 consists of 35 items measuring eight dimensions of health: physical functioning (10 items), role limitations caused by physical health problems (4 items), bodily pain (2 items), general health (5 items), vitality (4 items), social function (2 items), role limitations caused by emotional problems (3 items), and mental health (5 items). In the scoring of the questionnaire, item scores are transformed into a 0-100 scale in the 8 dimensions, with higher scores indicating better HRQL. The reliability and the validity of the RAND-36 have been confirmed to be good and the internal consistency of the domains satisfactory, with Cronbach's alphas $>0.80$ for all eight scales [24, 25].

\section{Depression}

Symptoms of depression were assessed using the Beck Depression Inventory-II (BDI-II) [28]. BDI-II consists of 21 items rated from 0 to 3 total sum ranging from 0 to 63 points with a higher number indicating more depressive symptoms. The items assess symptoms corresponding to criteria for diagnosing depressive disorders according to the Diagnostic and Statistical Manual of Mental Disorders (4th ed.; American Psychiatric Association, 1994). The instrument has shown good psychometric properties including high reliability, capacity to discriminate between depressed and non-depressed subjects, and adequate concurrent, content, and structural validity [29].

\section{Medical late effects}

Potential medical late effects were classified with the Common Terminology Criteria for Adverse Events (CTCAE) version 5.0. With the CTCAE, medical late effects are classified from one to five. One stands for mild or no medical late effects, two for moderate, three for severe, four for immediately life threatening, and five for death caused by a medical late effect. For the present study, the CTCAE was dichotomized when used in the regression models according to "mild or no events" and "moderate or above."

\section{Cognitive function}

Cognitive function was assessed using the Performance Intelligence Quotient (PIQ) from the Wechsler Adult Intelligent Scale (WAIS), third version. The scoring of PIQ is based on the normal distribution of the population $($ mean $=100, \mathrm{SD}=15)$. Previous research has shown that PIQ is a significant predictor of both educational level and employment status in childhood BT survivors [26].

\section{Statistical analyses}

The level of HRQL was compared between male survivors and male controls in all dimensions of RAND-36 using independent $t$ tests. The same procedure was carried out for female survivors and controls, and for comparison of female to male survivors. For survivors, regression models were fitted for each domain of the RAND-36 with the following included as independent variables: gender, age at 
diagnosis (<age of 13 vs. $\geq$ age of 13), chemotherapy (yes/ no), CTCAE (1 vs. > 1) (yes/no), employment (including being a student) (yes/no), education level (elementary vs. above elementary), relationship status (yes/no), PIQ, and symptoms of depression.

\section{Results}

\section{Participants}

\section{BT survivors}

Of the 127 potentially eligible participants, 74 individuals participated in the data collection (including clinical assessment, neurocognitive tests, and assessment of psychological function). Of these, 60 (81\%) completed the RAND-36 and participated in the present study: 21 (35\%) women and 39 $(65 \%)$ men. There was no difference between responders and non-responders in terms of age at diagnosis, current age, CTCAE, follow-up time, or chemotherapy.

The mean age of the participants was 28.1 years $(\mathrm{SD}=6.8)$. Mean age at diagnosis was 8.5 years $(\mathrm{SD}=4.3)$ and the mean follow-up time was 19.1 years $(\mathrm{SD}=5.9)$. The most common tumor type was the glial cell tumor $(45 \%)$. All participants had received RT, $63 \%$ had been treated with chemotherapy, and $58 \%$ had received a ventriculoperitoneal shunt. A minority were married/had cohabiting partnership (27\%), 65\% ( $n=39)$ were working/studying, and $10 \%$ $(n=6)$ had a university degree. For the full report of the demographic, clinical, and psychosocial characteristics, see Table 1.

\section{Control group}

In the control group, 146 individuals participated. Of these, $65 \%$ were women $(n=95)$ and $35 \%$ men $(n=51)$. The mean age was 25.0 years $(\mathrm{SD}=5.1)$. A majority of the participants in the control group were married or had a cohabiting partnership (57\%, $n=83), 81 \%(n=118)$ were working/studying, and $9 \%(n=14)$ had a university degree. See Table 1 for the presentation of the demographic and psychosocial variables for the control group.

\section{Health-related quality of life}

Female survivors' scores in the dimensions of RAND-36 ranged from 63.9 (vitality) to 82.3 points (physical functioning). Male survivors' scores ranged from 63.2 (vitality) to 92.7 points (physical functioning). Comparing BT survivors and controls by gender showed that female survivors reported significantly lower HRQL in the dimension of physical functioning $(p<0.001)$ than controls. No other
HRQL dimensions differed between female survivors and controls (see Fig. 1). Among men, BT survivors reported significantly lower scores than controls in the following five dimensions: physical functioning $(p<0.05)$; general health $(p<0.05)$; vitality $(p<0.01)$; social functioning $(p<0.05)$; and role limitations caused by emotional problems $(p<0.05)$. No differences were observed in the other dimensions of HRQL for men (see Fig. 2). Lastly, in comparing HRQOL scores between female and male BT survivors, mean values did not differ aside from in the domain physical functioning where males reported significantly higher scores than females $(p=0.001)$. See also Table 2 for a comparison between survivors and controls.

\section{Factors associated with health-related quality of life}

The multivariable linear regression models showed that receiving the $\mathrm{BT}$ diagnosis during adolescence compared to at an earlier age predicted lower HRQL in the dimensions role limitations due to physical problems, social functioning, and role limitations due to emotional problems. Having a score above 1 in CTCAE was associated with lower HRQL in the dimensions general health and vitality. Not working/ studying was related to lower HRQL with regard to bodily pain. Lastly, symptoms of depression were related to lower HRQL in all the domains. For full results, see Table 3.

\section{Discussion}

In this study, HRQL was investigated in long-term survivors of childhood BT. Results showed that male survivors report significantly lower HRQL than male controls in five of the eight domains of HRQL: physical functioning, general health, vitality, social functioning, and role limitations caused by emotional problems. Female survivors on the other hand reported comparable levels to female controls in all domains, except in physical functioning. Furthermore, our results showed that predictors of low HRQL in longterm survivors of childhood BT include a higher burden of late effects, not working/studying, having been diagnosed with BT during adolescence, and the occurrence of depressive symptoms.

Previous studies have reported either no effect of gender on HRQL [31] or a pronounced negative effect on HRQL among female survivors of childhood BT [23, 32]. In contrast, our findings show that male childhood BT survivors reported more areas of impaired HRQL than female survivors when comparing to gender-matched controls. This difference in findings can be related to methodological issues in previous research such as the use of gender-mixed samples and/or lack of gender-specific comparison groups (e.g., $[32,33])$. As females in general report lower HRQL 
Table 1 Demographics and clinical variables for brain tumor (BT) survivors and control group

\begin{tabular}{|c|c|c|c|c|c|c|}
\hline \multirow[b]{2}{*}{$n(\%)$ or mean $(\mathrm{SD})$} & \multicolumn{3}{|l|}{ BT survivors } & \multicolumn{3}{|l|}{ Control group } \\
\hline & Total $(n=60)$ & Women $(n=21)$ & $\operatorname{Men}(n=39)$ & Total $(n=146)$ & Women $(n=95)$ & $\operatorname{Men}(n=51)$ \\
\hline Age & $28.1(6.8)$ & $30.2(7.6)$ & $27.0(6.0)$ & $25.0(5.1)$ & $24.6(5.4)$ & $25.8(4.4)$ \\
\hline \multicolumn{7}{|l|}{ Civil status } \\
\hline Married & $8(13.3)$ & $6(28.6)$ & $2(5.1)$ & $32(22.1)$ & $20(21.3)$ & $12(23.5)$ \\
\hline $\begin{array}{l}\text { Cohabiting partner- } \\
\text { ship }\end{array}$ & $8(13.3)$ & $4(19.0)$ & $4(10.3)$ & $51(35.2)$ & $36(38.3)$ & $15(29.4)$ \\
\hline $\begin{array}{l}\text { Not married/cohab- } \\
\text { iting partnership }\end{array}$ & $44(73.3)$ & $11(52.4)$ & $33(84.6)$ & $62(42.8)$ & $38(40.4)$ & $24(47.1)$ \\
\hline \multicolumn{7}{|l|}{ Employment } \\
\hline Working & $23(38.3)$ & $11(52.4)$ & $12(30.8)$ & $84(59.6)$ & $47(52.2)$ & $37(72.5)$ \\
\hline Studying & $16(26.7)$ & $4(19.0)$ & $12(30.8)$ & $34(24.1)$ & $24(26.7)$ & $10(19.6)$ \\
\hline Unemployed & $10(16.7)$ & $4(19.0)$ & $6(15.4)$ & $10(7.1)$ & $6(6.7)$ & $4(7.8)$ \\
\hline Retired & $11(18.3)$ & $2(9.5)$ & $9(23.1)$ & 0 & 0 & 0 \\
\hline Other & 0 & 0 & 0 & $13(9.2)$ & $13(14.4)$ & 0 \\
\hline $\mathrm{BDI}^{-\mathrm{II}^{\mathrm{a}}}$ & $6.8(7.2)$ & $9.4(9.8)$ & $5.5(5.3)$ & $5.7(9.0)$ & $7.1(10.0)$ & $2.9(6.1)$ \\
\hline $\begin{array}{l}\text { Clinical cutoff for } \\
\text { depression }\end{array}$ & $3(5.2)$ & $2(10.0)$ & $1(2.6)$ & $13(8.0)$ & $10(10.5)$ & $3(5.9)$ \\
\hline \multicolumn{7}{|l|}{ BT survivors variables } \\
\hline Age at diagnosis & $8.5(4.3)$ & $9.0(4.6)$ & $8.2(4.2)$ & & & \\
\hline $\begin{array}{l}\text { Follow-up time in } \\
\text { years }\end{array}$ & $19.1(5.9$, range $5-33)$ & $20.5(6.1$, range $9-33)$ & $18.3(5.7$, range $5-30)$ & & & \\
\hline \multicolumn{7}{|l|}{ Tumor type } \\
\hline Glial cell tumor & $27(45.0)$ & $13(61.9)$ & $14(35.9)$ & & & \\
\hline $\begin{array}{l}\text { Embryonal cell } \\
\text { tumor }\end{array}$ & $20(33.3)$ & $6(28.6)$ & $14(35.9)$ & & & \\
\hline Other & $12(20.0)$ & $2(9.5)$ & $10(25.6)$ & & & \\
\hline Unknown & $1(1.7)$ & 0 & $1(2.6)$ & & & \\
\hline \multicolumn{7}{|l|}{ Irradiation } \\
\hline $\begin{array}{l}\text { Cranial or cranio- } \\
\text { spinal }\end{array}$ & $28(46.7)$ & $7(33.3)$ & $21(53.8)$ & & & \\
\hline Local & $32(53.3)$ & $14(66.7)$ & $19(46.2)$ & & & \\
\hline \multicolumn{7}{|c|}{ Ventriculo-peritoneal shunt } \\
\hline Yes & $35(58.3)$ & $11(52.4)$ & $24(61.5)$ & & & \\
\hline No & $25(41.7)$ & $10(47.6)$ & $15(38.5)$ & & & \\
\hline \multicolumn{7}{|l|}{ Chemotherapy } \\
\hline Yes & $38(63.3)$ & $13(61.9)$ & $25(64.1)$ & & & \\
\hline No & $22(36.7)$ & $8(38.1)$ & $14(35.9)$ & & & \\
\hline \multicolumn{7}{|l|}{$\mathrm{CTCAE}^{\mathrm{c}}$} \\
\hline 1 & $23(38.3)$ & $5(23.8)$ & $18(46.2)$ & & & \\
\hline 2 & $22(36.7)$ & $7(33.3)$ & $15(38.5)$ & & & \\
\hline 3 & $15(25.0)$ & $9(42.9)$ & $6(15.4)$ & & & \\
\hline PIQ & $88.4(13.8)$ & $89.7(13.9)$ & $87.7(13.9)$ & & & \\
\hline
\end{tabular}

${ }^{a}$ Norm data on BDI-II in the age group, mean $(\mathrm{SD})$, women $=9.81$ (8.67), men $=8.22$ (8.06) [30]

${ }^{\mathrm{b}} \mathrm{Cutoff}$ value of 20 or higher indicative of at least moderate level of depressive symptoms

${ }^{\mathrm{c}}$ No scores of 4 or 5 were recorded

BDI-II, Beck Depression Inventory-II; CTCAE, Common Terminology Criteria for Adverse Events; PIQ, Performance Intelligence Quotient

than males [34], which also was the general pattern in our results, the use of these designs may lead to the conclusion that female gender is a risk factor for impaired HRQL following childhood BT. Thus, comparing male survivors to male controls and female survivors to female controls is essential in order to determine the gender effect on HRQL 
Fig. 1 Mean values for the eight RAND-36 domains for female BT survivors and female controls. Significant differences indicated by $* * * p<0.001$. PF, limitations caused by physical health problems; BP, bodily pain; GH, general health; VT, $\mathrm{RE}$, role limitations caused by emotional problems; $\mathrm{MH}$, mental health physical functioning; RP, role vitality; SF, social function;

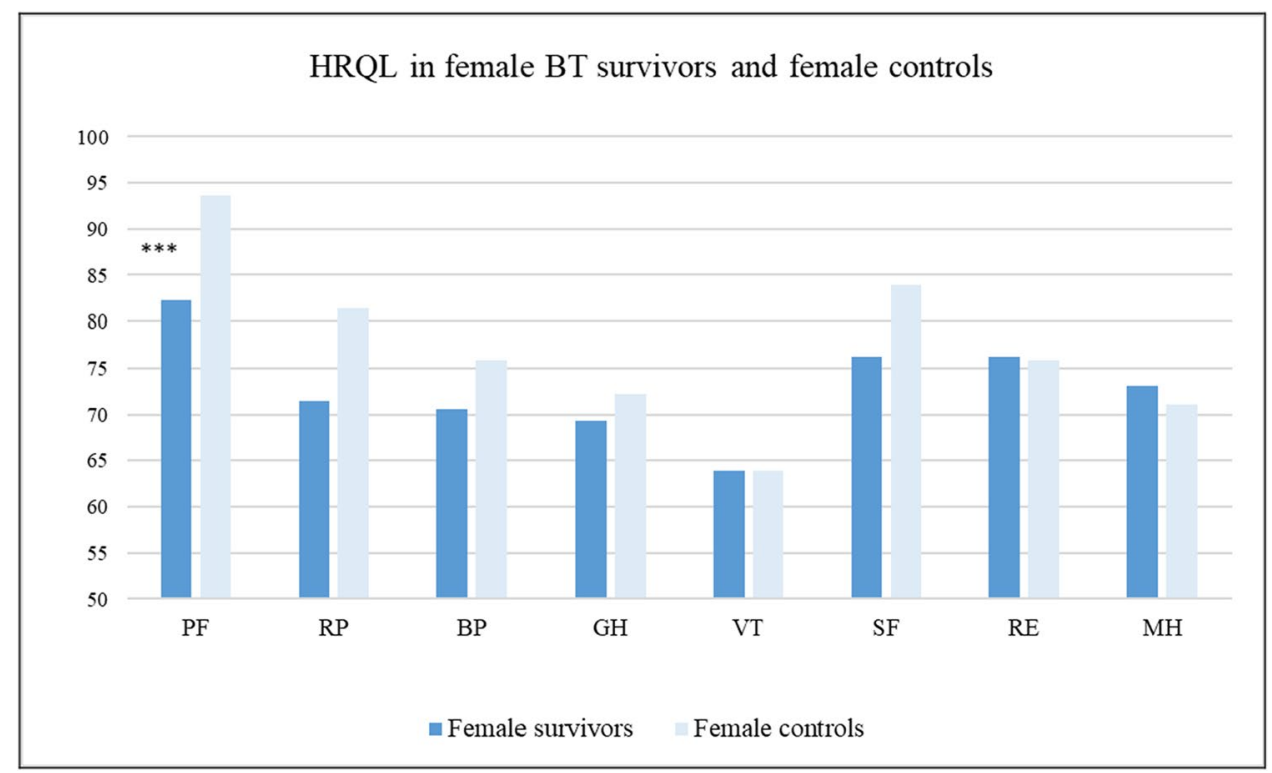

Fig. 2 Mean values for the eight RAND-36 domains for male BT survivors and male controls. Significant differences indicated by $* p<0.05 ; * * p<0.01$. PF, physical functioning; RP, role limitations caused by physical health problems; BP, bodily pain; GH, general health; VT, vitality; SF, social function; $\mathrm{RE}$, role limitations caused by emotional problems; $\mathrm{MH}$, mental health

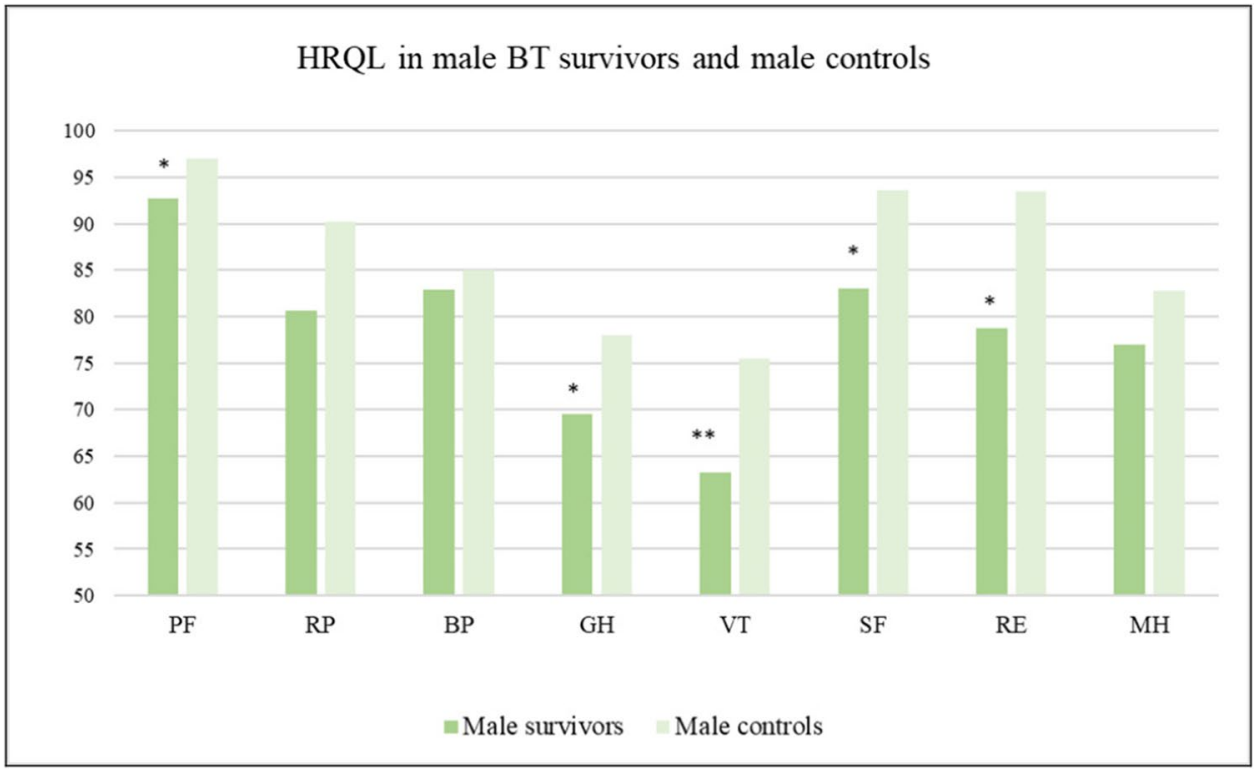

following BT. Importantly, our findings correspond with results from a study using gender-specific comparison data in long-term survivors of childhood cancer (all diagnoses) where depressive symptoms were reported to be comparably higher among male survivors [35].

One factor that should be discussed in relation to the effect of gender on HRQL in this population is the proportion of the male survivors who were in an intimate partner relationship compared to the proportion of female survivors: $15 \%$ vs. $48 \%$. These figures correspond with previous results reporting that male $\mathrm{BT}$ survivors less often are married compared to female survivors [36, 37]. Also, it should be acknowledged that in the control sample, the difference in prevalence of intimate relationships was smaller $(60 \%$ among females and 53\% among males). As having an intimate partner relationship is a well-known predictor of quality of life and overall well-being [38-40], the lower rate of intimate relationship among male BT survivors could be related to the lower levels of HRQL. Furthermore, and possibly related to this issue, male survivors in our study reported lower levels of HRQL in the area of "social function." In previous research, it has been shown that survivors of childhood BT assess social aspects to be very important, even more so than functionality, for their quality of life [41]. Thereby, to improve the possibility to develop and maintain relationships, our findings suggest that in particular male 
Table 2 Descriptive statistics for RAND-36 domains presented by gender. Student's $t$ tests for differences in mean between female BT survivors and female controls, and between male BT survivors and male controls. Bold text indicates a significant $p$ value

\begin{tabular}{|c|c|c|c|c|c|c|}
\hline \multirow[b]{2}{*}{ RAND-36 domains } & \multicolumn{3}{|c|}{ Women, mean (SD) } & \multicolumn{3}{|c|}{ Men, mean (SD) } \\
\hline & BT survivors & Comparison group ${ }^{a}$ & $t$ test & BT survivors & Comparison group ${ }^{\mathrm{a}}$ & $t$ test \\
\hline Physical functioning & $82.3(15.0)$ & $93.6(10.9)$ & $<0.001$ & $92.7(8.6)$ & $97.0(7.3)$ & 0.012 \\
\hline Role limitations - physical health & $71.4(29.9)$ & $81.4(28.6)$ & 0.156 & $80.6(32.0)$ & $90.2(26.5)$ & 0.129 \\
\hline Bodily pain & $70.6(26.8)$ & $75.9(22.8)$ & 0.348 & $82.9(20.4)$ & $85.0(20.6)$ & 0.638 \\
\hline General health & $69.3(17.9)$ & $72.2(17.4)$ & 0.507 & $69.5(19.0)$ & $78.0(17.5)$ & $\mathbf{0 . 0 2 9}$ \\
\hline Vitality & $63.9(24.1)$ & $63.9(18.6)$ & 0.990 & $63.2(22.9)$ & $75.4(17.6)$ & 0.005 \\
\hline Social functioning & $76.2(18.9)$ & $83.9(21.7)$ & 0.135 & $83.0(22.1)$ & $93.6(13.3)$ & 0.010 \\
\hline Role limitations - emotional problems & $71.4(38.4)$ & $75.9(33.3)$ & 0.591 & $78.7(34.9)$ & $93.5(22.1)$ & 0.029 \\
\hline Mental health & $73.1(21.8)$ & $71.1(18.4)$ & 0.659 & $77.0(16.0)$ & $82.7(14.1)$ & 0.079 \\
\hline
\end{tabular}

${ }^{\text {a }}$ Results for the comparison group were in line with norms for the age group in all domains of the RAND-36 [24]

Table 3 Multivariable linear regression models for the eight dimensions of RAND-36 reported by unstandardized coefficient B. Bold text indicates a significant $p$ value

\begin{tabular}{|c|c|c|c|c|c|c|c|c|}
\hline $\begin{array}{l}\text { RAND-36 } \\
\text { dimension }\end{array}$ & $\begin{array}{l}\text { Physical func- } \\
\text { tion }\end{array}$ & $\begin{array}{l}\text { Role limita- } \\
\text { tions - physical } \\
\text { problems }\end{array}$ & Bodily pain & General health & Vitality & Social function & $\begin{array}{l}\text { Role limitations } \\
\text { - emotional } \\
\text { problems }\end{array}$ & Mental health \\
\hline $\begin{array}{l}\text { Age at diag- } \\
\text { nosis }\end{array}$ & $\begin{array}{l}-0.37 \\
p=0.907\end{array}$ & $\begin{array}{c}-26.80 \\
p=0.003\end{array}$ & $\begin{array}{l}-10.30 \\
p=0.154\end{array}$ & $\begin{array}{l}-6.29 \\
p=0.316\end{array}$ & $\begin{array}{l}-3.94 \\
p=0.487\end{array}$ & $\begin{array}{c}-14.08 \\
p=0.029\end{array}$ & $\begin{array}{c}-22.93 \\
p=0.013\end{array}$ & $\begin{array}{l}-2.10 \\
p=0.627\end{array}$ \\
\hline BDI-II & $\begin{array}{l}-0.58 \\
p=0.004\end{array}$ & $\begin{array}{l}-1.88 \\
p=0.001\end{array}$ & $\begin{array}{l}-0.93 \\
p=0.031\end{array}$ & $\begin{array}{l}-1.15 \\
p=0.003\end{array}$ & $\begin{array}{l}-2.05 \\
p<0.001\end{array}$ & $\begin{array}{l}-0.98 \\
p=0.009\end{array}$ & $\begin{array}{l}-3.24 \\
p<0.001\end{array}$ & $\begin{array}{l}-1.98 \\
p<0.001\end{array}$ \\
\hline CTCAE & $\begin{array}{l}-4.76 \\
p=0.101\end{array}$ & $\begin{array}{l}-11.39 \\
p=0.146\end{array}$ & $\begin{array}{l}-4.75 \\
p=0.448\end{array}$ & $\begin{array}{c}-11.41 \\
p=0.041\end{array}$ & $\begin{array}{c}-13.08 \\
p=0.011\end{array}$ & $\begin{array}{l}5.09 \\
p=0.354\end{array}$ & $\begin{array}{l}3.38 \\
p=0.671\end{array}$ & $\begin{array}{l}2.60 \\
p=0.492\end{array}$ \\
\hline $\begin{array}{l}\text { Working/study- } \\
\text { ing vs not }\end{array}$ & $\begin{array}{l}-3.17 \\
p=0.303\end{array}$ & $\begin{array}{l}9.01 \\
p=0.283\end{array}$ & $\begin{array}{l}-15.47 \\
p=0.025\end{array}$ & $\begin{array}{l}1.45 \\
p=0.804\end{array}$ & $\begin{array}{l}-1.85 \\
p=0.728\end{array}$ & $\begin{array}{l}-6.11 \\
p=0.300\end{array}$ & $\begin{array}{l}-3.59 \\
p=0.675\end{array}$ & $\begin{array}{l}-3.46 \\
p=0.396\end{array}$ \\
\hline
\end{tabular}

In addition to the variables reported in the table, the following variables were also controlled for in all models: gender, PIQ, education, chemotherapy, partnership, and ventriculoperitoneal shunt. These variables were non-significant for all outcomes

BDI-II, Beck Depression Inventory-II; CTCAE, Common Terminology Criteria for Adverse Events

survivors could be screened for social ability and function and if necessary offered support interventions such as social skills training.

The results showed that both male and female survivors reported lower scores in the physical functioning domain compared to controls. This finding can be related to the wellknown high burden of late effects among survivors [3-5]. In our sample, a large majority of participants were assessed as having at least a moderate burden of late effects, and the results underscore that these late effects have a negative impact on HRQL. Since all participants in the present study had received $\mathrm{RT}$, which is a more intensive treatment than only surgery or chemotherapy, the burden of late effects can be expected to be particularly high in our sample. Still, our findings highlight the need for adequate care and treatment of medical conditions in long-term childhood BT survivors in order to improve HRQL in this population.

In this study, medical, physical, neurocognitive, psychological, and socio-demographic factors associated with HRQL in long-term survivors of childhood BT were examined. Results showed that having a higher burden of late effects, having been diagnosed with BT during adolescence, not currently working/studying, and reporting depressive symptoms were significant predictors of lower HRQL. Our findings replicate previous results showing that older age at diagnosis is a predictor of a lower level of HRQL $[19,20]$, and thereby highlight that individuals diagnosed with BT during adolescence are at increased risk of longterm impairment of their quality of life. In particular, our results show that $\mathrm{BT}$ during adolescence is related to lower HRQL in social function and perceived role limitations due to emotional problems, which should be acknowledged by clinicians. The other treatment-related variables in the analyses (chemotherapy and ventriculoperitoneal shunt) were unrelated to HRQL, which supports the conclusion that treatment variables have a minor effect on the quality of life in long-term survivors [8]. However, previous research has concluded that the treatment with RT is associated to lower HRQL in childhood cancer survivors. In our sample, all participants had received RT. Thereby, RT could not be 
included as a factor in the analyses. Furthermore, cognitive function, assessed using PIQ, did not predict HRQL. These results contradict previous findings where cognitive function has been associated with lower HRQL in survivors of childhood BT [21]. Our findings thereby suggest that cognitive function per se does not explain the lower HRQL seen in this population, but rather is a factor related to other predictors such as unemployment, which in turn are related to impaired quality of life. Still, it is possible that specific neurocognitive functions would have been related to HRQL; however, it was beyond the scope of this study to investigate further. Lastly, both the burden of late effects and occurrence of depressive symptoms were significant predictors of HRQL. Of particular importance were depressive symptoms, which were associated with all areas of HRQL. This finding is in line with previous results showing that depressive symptoms are strongly associated with impairment in HRQL in other clinical and non-clinical populations. It has even been shown that the effect of depressive symptoms on HRQL is comparable with the effect of the chronic health conditions arthritis, diabetes, and hypertension [42]. Furthermore, it has been suggested that depressive symptoms also may interact with the medical conditions per se to further decrease quality of life, described as an "amplification effect." Thereby, screening for depressive symptoms should be prioritized in childhood BT follow-up care $[43,44]$ and by early identification and provision of adequate treatment of depression in this population, improvement in both mental health HRQL, and possibly also medical conditions, could be achieved.

\section{Strengths and limitations}

The current study has several important strengths as well as limitations. First, the control group was not fully agematched to the survivors. However, as HRQL changes only minimally during young adulthood according to standardized norms of the RAND-36 [30], this difference should be considered insignificant. The control group was not fully matched on the living area of the survivors, which should be acknowledged. Another limitation is the cross-sectional design of the study, hampering conclusions with regard to causality. Future studies using a longitudinal design are encouraged to determine the relationship between HRQL and variables such as symptoms of depression and relationship status. Another possible limitation is the heterogeneous sample in terms of histology of BT and follow-up time in combination with the rather small number of participants, thereby impeding subgroup analyses. Also, since the population of long-term survivors of childhood BT is small, and the sample size in this study therefore also was rather small, the risk of underpowered analyses should be taken into consideration when interpreting the results. Another issue that should be brought to attention is that some of the most functionally and cognitively impaired survivors in the cohort were not able to complete the cognitive testing and/or the BDI-II and the RAND-36, which should be acknowledged in terms of generalizability of the results. Also, as some of the participants with low levels of function were assisted in completing the data collection, this might have induced some bias. Still, we believe this was the preferable choice compared to excluding these participants and missing out on results from them. Lastly, it should be acknowledged that since all participants in the present study had been treated with RT, study results should primarily be generalized to this group of BT survivors. Strengths of the study on the other hand include the very rigorous method for collecting data and the use of validated measurements. Furthermore, the use of gender-specific comparison groups is an important strength of this study. Again, due to the relatively small sample size, however, it was not possible to conduct separate regression analyses for male and female survivors. Future studies should prioritize collecting larger samples and reliable comparison data, for example, by using multinational collaborations, to allow for reliable analyses on the predictors of HRQL in long-term survivors of childhood BT.

\section{Conclusion}

The present study showed that male long-term survivors of childhood BT report significantly lower levels of HRQL than male controls in five of the eight domains of HRQL: physical functioning, general health, vitality, social functioning, and role limitations caused by emotional problems. Female survivors on the other hand report comparable levels to female controls in all domains except in physical functioning. These results should be acknowledged by clinicians and care providers in order to identify survivors who experience impaired HRQL, and to provide adequate support and interventions to allow for improvements in the quality of life among these individuals. Specifically, our results point to the association between low HRQL and a higher burden of late effects, not working/studying, and the occurrence of depressive symptoms, which should be addressed and targeted with appropriate interventions. By providing adequate medical or psychological treatment for symptoms of depression to long-term survivors of childhood BT, HRQL could be improved as well.

Author contribution Conceptualization: L.L., T.R., E.W., A.H., T.L., K.S., H.R., M.O., H.P., M.H., P.L., P.A., A.W., A.H-S.; Methodology: L.L., T.R., E.W., A.H., A.W., A.H-S.; Formal analysis: L.L., T.R., A.H-S.; Investigation: L.L., T.R., E.W., A.H.,.L T., K.S., H.R., M.O., H.P., M.H., P.L., P.A., A.W., A.H-S.; Writing - original draft: L.L., T.R., A.H-S.; Writing - review and editing: L.L., T.R., E.W., A.H., T.L., K.S., H.R., M.O., H.P., M.H., P.L., P.A., A.W., A.H-S. 
Funding Open access funding provided by Uppsala University. This study was funded by Special State Grants for Health Research in the Department of Pediatric and Adolescence, Oulu University Hospital, Finland (to T.R.); the Väre Foundation for Pediatric Cancer Research, Finland (to T.R.); the Foundation of Päivikki and Sakari Sohlberg, Finland (to T.R.); the Foundation of Arvo and Lea Ylppö, Finland (to T.R.); the Foundation for Pediatric Research, Finland (to T.R.); the Foundation of Emil Aaltonen, Finland (to T.R.); the Cancer Society of Finland (to H.R. and A.H.-S.); the Foundation of Thelma Mäkikyrö, Finland (to T.R.); the Cancer Foundation of Northern Finland (to T.R.); the Aamu Finnish Childhood Cancer Foundation (to T.R.); the Foundation of Alma and K. A. Snellman, Finland (to T.R.); the Foundation of Märta Donner, Finland (to T.R.); and by the Swedish Childhood Cancer Fund (to L.L).

Data availability Data are not publicly available due to ethical restrictions. Data that support the findings of this study are available from the corresponding author, upon reasonable request and with necessary ethics approval.

Code availability Not applicable.

\section{Declarations}

Ethics approval This study was performed in line with the principles of the Declaration of Helsinki. Approval was granted by the institutional review boards of the Oulu, Kuopio, Turku, Tampere, and Helsinki university hospitals, Finland (reference numbers 73/2010 and 159/2010).

Consent to participate Informed consent was obtained from all individual participants included in the study.

Consent for publication Patients signed informed consent regarding publishing their data.

Conflict of interest T.R. has received financial support for attending symposia from the Cancer Foundation of Northern Finland; Foundation of Arvo and Lea Ylppö, Finland; the Foundation for Pediatric Research, Finland; and PtcBio, Orion Pharma, and Biogenes; P.A. has received financial support for attending symposia from AbbVie and Alexion; P.L. has received financial support for attending symposia from Shire, Sobi, Bayer, and the Cancer Foundation of Finland; T.L. has received a speaker honorarium from Actelion Pharmaceuticals and Biomarin; The other authors report no conflict of interest.

Open Access This article is licensed under a Creative Commons Attribution 4.0 International License, which permits use, sharing, adaptation, distribution and reproduction in any medium or format, as long as you give appropriate credit to the original author(s) and the source, provide a link to the Creative Commons licence, and indicate if changes were made. The images or other third party material in this article are included in the article's Creative Commons licence, unless indicated otherwise in a credit line to the material. If material is not included in the article's Creative Commons licence and your intended use is not permitted by statutory regulation or exceeds the permitted use, you will need to obtain permission directly from the copyright holder. To view a copy of this licence, visit http://creativecommons.org/licenses/by/4.0/.

\section{References}

1. Allemani C, Matsuda T, di Carlo V, Harewood R, Matz M, Nikšić $M$ et al (2018) Global surveillance of trends in cancer survival 2000-14 (CONCORD-3): analysis of individual records for 37513025 patients diagnosed with one of 18 cancers from 322 population-based registries in 71 countries. Lancet 391(10125):1023-1075

2. Jemal A, Ward EM, Johnson CJ, Cronin KA, Ma J, Ryerson $\mathrm{AB}$ et al (2017) Annual report to the nation on the status of cancer, 1975-2014, Featuring Survival. J Natl Cancer Inst 109(9):djx030. https://doi.org/10.1093/jnci/djx030

3. Turner CD, Rey-Casserly C, Liptak CC, Chordas C (2009) Late effects of therapy for pediatric brain tumor survivors. J Child Neurol 24(11):1455-1463. https://doi.org/10.1177/0883073809 341709

4. Armstrong GT (2010) Long-term survivors of childhood central nervous system malignancies: the experience of the Childhood Cancer Survivor Study. Eur J Paediatr Neurol 14:298-303

5. Hudson MM, Mertens AC, Yasui Y et al (2003) Health status of adult long-term survivors of childhood cancer: A Report from the childhood cancer survivor study. JAMA 290(12):15831592. https://doi.org/10.1001/jama.290.12.1583

6. Gurney J, Kadan-Lottick N, Packer R, Neglia J, Sklar C, Punyko J et al (2003) Endocrine and cardiovascular late effects among adult survivors of childhood brain tumors. Cancer 97(3):663-673

7. Mulhern RK, Butler RW (2004) Neurocognitive sequelae of childhood cancers and their treatment. Pediatr Rehabil 7(1):114. https://doi.org/10.1080/13638490310001655528

8. Zheng DJ, Krull KR, Chen Y, Diller L, Yasui Y, Leisenring W et al (2018) Long-term psychological and educational outcomes for survivors of neuroblastoma: a report from the Childhood Cancer Survivor Study. Cancer 124(15):3220-3230

9. Karimi M, Brazier J (2016) Health, Health-related quality of life, and quality of life: what is the difference? PharmacoEconomics 34(7):645-649

10. Bullinger M, Quitmann J (2014) Quality of life as patientreported outcomes: principles of assessment. Dialogues Clin Neurosci 16(2):137-145

11. Maddrey AM, Bergeron JA, Lombardo ER, McDonald NK, Mulne AF, Barenberg PD et al (2005) Neuropsychological performance and quality of life of 10 year survivors of childhood medulloblastoma. J Neuro-Oncol 72(3):245-253

12. Crom DB, Li Z, Brinkman TM, Hudson MM, Armstrong GT, Neglia J et al (2014) Life satisfaction in adult survivors of childhood brain tumors. J Pediatr Oncol Nurs 31(6):317-326

13. Meeske KA, Patel SK, Palmer SN, Nelson MB, Parow AM (2007) Factors associated with health-related quality of life in pediatric cancer survivors. Pediatr Blood Cancer 49(3):298-305

14. Wengenroth L, Gianinazzi ME, Rueegg CS, Lüer S, Bergstraesser E, Kuehni CE et al (2015) Health-related quality of life in young survivors of childhood cancer. Qual Life Res 24(9):2151-2561

15. Duckworth J, Nayiager T, Pullenayegum E, Whitton A, Hollenberg R, Horsman J et al (2015) Health-related quality of life in long-term survivors of brain tumors in childhood and adolescence: a serial study spanning a decade. J Pediatr Hematol Oncol 37(5):362-367. https://doi.org/10.1097/MPH.0000000000000365

16. Stam H, Grootenhuis MA, Caron HN, Last BF (2006) Quality of life and current coping in young adult survivors of childhood cancer: positive expectations about the further course of the disease were correlated with better quality of life. Psycho-Oncology 15(1):31-43 
17. Poretti A, Grotzer M, Ribi K, Schönle E, Boltshauser E (2004) Outcome of craniopharyngioma in children: long-term complications and quality of life. Dev Med Child Neurol 46(4):220-229. https://doi.org/10.1017/S0012162204000374

18. Brinkman TM, Li Z, Neglia JP, Gajjar A, Klosky JL, Allgood R et al (2013) Restricted access to the environment and quality of life in adult survivors of childhood brain tumors. J Neuro-Oncol 111(2):195-203

19. Macartney G, Harrison MB, VanDenKerkhof E, Stacey D, McCarthy P (2014) Quality of life and symptoms in pediatric brain tumor survivors: a systematic review. J Pediatr Oncol Nurs 31(2):65-77

20. Aarsen FK, Paquier PF, Reddingius RE, Streng IC, Arts WFM, Evera-Preesman $\mathrm{M}$ et al (2006) Functional outcome after lowgrade astrocytoma treatment in childhood. Cancer 106(2):396-402

21. Reimers TS, Mortensen EL, Nysom K, Schmiegelow K (2006) Health-related quality of life in long-term survivors of childhood brain tumors. Pediatr Blood Cancer 53(6):1086-1091

22. Schulte F, Barrera M (2010) Social competence in childhood brain tumor survivors: a comprehensive review. Support Care Cancer 18:1499-1513. https://doi.org/10.1007/s00520-010-0963-1

23. Alessi D, Dama E, Barr R, Mosso ML, Maule M, Magnani C et al (2007) Health-related quality of life of long-term childhood cancer survivors: a population-based study from the Childhood Cancer Registry of Piedmont, Italy. Eur J Cancer 43(17):2545-2552

24. Hays RD, Morales LS (2001) The RAND-36 measure of healthrelated quality of life. Ann Med 33(5):350-357. https://doi.org/ 10.3109/07853890109002089

25. Ohlsson-Nevo E, Hiyoshi A, Norén P, Möller M, Karlsson J (2021) The Swedish RAND-36: psychometric characteristics and reference data from the Mid-Swed Health Survey. J Patient Rep Outcomes 5:66

26. Remes TM, Hovén E, Ritari N, Pohjasniemi H, Puosi R, Arikoski PM et al (2021) Neurocognitive impairment, employment, and social status in radiotherapy-treated adult survivors of childhood brain tumors. Neuro-Oncol Pract 8(3):266-277

27. Harila MJ, Salo J, Lanning M, Vilkkumaa I, Harila-Saari AH (2010) High health-related quality of life among long-term survivors of childhood acute lymphoblastic leukemia. Pediatr Blood Cancer 55(2):331-336

28. Beck AT, Steer RA, Brown GK (1996) Manual for the Beck Depression Inventory-II. Psychological Corporation, San Antonio

29. Wang YP, Gorenstein C (2013) Psychometric properties of the Beck Depression Inventory-II: a comprehensive review. Rev Bras Psiquiatr 35(4):416-431

30. Garratt AM, Stavem K (2017) Measurement properties and normative data for the Norwegian SF-36: results from a general population survey. Health Qual Life Outcomes 15:(51)

31. Reimers TS, Mortensen EL, Nysom K, Schmiegelow K (2009) Health-related quality of life in long-term survivors of childhood brain tumors. Pediatr Blood Cancer 53(6):1086-1091

32. Zebrack BJ, Zeltzer LK, Whitton J, Mertens AC, Odom L, Berkow R, Robison LL (2002) Psychological outcomes in long-term survivors of childhood leukemia, Hodgkin's disease, and nonHodgkin's lymphoma: a report from the Childhood Cancer Survivor Study. Pediatrics 110(1 Pt 1):42-52. https://doi.org/10.1542/ peds.110.1.42

33. Wengenroth L, Gianinazzi ME, Rueegg CS, Lüer S, Bergstraesser E, Kuehni CE et al (2015) Health-related quality of life in young survivors of childhood cancer. Qual Life Res 24(9):2151-2161

34. Fryback DG, Dunham NC, Palta M, Hanmer J, Buechner J, Cherepanov $\mathrm{P}$ et al (2007) US norms for six generic health-related quality-of-life indexes from the national health measurement study. Med Care 45(12):1162-1170

35. Oancea SC, Brinkman TM, Ness KK, Krull KR, Smith WA, Srivastava DK et al (2014) Emotional distress among adult survivors of childhood cancer. J Cancer Surviv 8(2):293-303

36. Langeveld NE, Stam H, Grootenhuis MA, Last BF (2002) Quality of life in young adult survivors of childhood cancer. Support Care Cancer 10(8):579-600. https://doi.org/10.1007/ s00520-002-0388-6

37. Janson C, Leisenring W, Cox C, Termuhlen AM, Mertens AC, Whitton JA et al (2009) Predictors of marriage and divorce in adult survivors of childhood cancers: a report from the childhood cancer survivor study. Cancer Epidemiol Biomarkers Prev 18(10):2626-2635

38. Quercioli C, Messina G, Barbini E, Carriero G, Fanì M, Nante N (2009) Importance of sociodemographic and morbidity aspects in measuring health-related quality of life: performances of three tools: comparison of three questionnaire scores. Eur J Health Econ 10(4):389-397

39. Han KT, Park EC, Kim JH, Kim SJ, Park S (2014) Is marital status associated with quality of life? Health Qual Life Outcomes 12:109. https://doi.org/10.1186/s12955-014-0109-0

40. Dush CMK, Amato PR (2005) Consequences of relationship status and quality for subjective well-being. J Soc Personal Relatsh 22(5):607-627

41. Gunn ME, Mört S, Arola M, Taskinen M, Riikonen P, Möttönen $M$ et al (2016) Quality of life and late-effects among childhood brain tumor survivors: a mixed method analysis. Psycho-Oncology 25:677-683

42. Gaynes B, Burns B, Tweed D, Erickson P (2002) Depression and health-related quality of life. J Nerv Ment Dis 12:799-806

43. Laoutidis ZG, Mathiak K (2013) Antidepressants in the treatment of depression/depressive symptoms in cancer patients: a systematic review and meta-analysis. BMC Psychiatry 16(13):140. https://doi.org/10.1186/1471-244X-13-140

44. Cuijpers P, van Straten A, Warmerdam L (2007) Behavioral activation treatments of depression: a meta-analysis. Clin Psychol Rev $27: 318-326$

Publisher's note Springer Nature remains neutral with regard to jurisdictional claims in published maps and institutional affiliations. 